University of Texas Rio Grande Valley

ScholarWorks @ UTRGV

Psychological Science Faculty Publications and

Presentations

College of Liberal Arts

8-11-2020

\title{
"I Went into This as One Person, and Then Came Out a Totally Different Person": Native LGBTQ2S+ Young Adults' Conceptions of Trauma
}

Rachel M. Schmitz

Oklahoma State University

Ruby Charak

The University of Texas Rio Grande Valley, ruby.charak@utrgv.edu

Follow this and additional works at: https://scholarworks.utrgv.edu/psy_fac

Part of the Feminist, Gender, and Sexuality Studies Commons, and the Psychology Commons

\section{Recommended Citation}

Schmitz, RM., \& Charak, R. (2020). "I Went into This as One Person, and Then Came Out a Totally Different Person": Native LGBTQ2S Young Adults' Conceptions of Trauma. Journal of Interpersonal Violence.

https://doi.org/10.1177/0886260520948523

This Article is brought to you for free and open access by the College of Liberal Arts at ScholarWorks @ UTRGV. It has been accepted for inclusion in Psychological Science Faculty Publications and Presentations by an authorized administrator of ScholarWorks @ UTRGV. For more information, please contact justin.white@utrgv.edu, william.flores01@utrgv.edu. 
"I Went into This as One Person, and Then Came Out a Totally Different Person": Native LGBTQ2S+ Young Adults' Conceptions of Trauma

\author{
Rachel M. Schmitz, Ph.D. a \\ Oklahoma State University \\ Department of Sociology
}

Ruby Charak, Ph.D.

The University of Texas Rio Grande Valley

Department of Psychological Science

aDirect all correspondence to Rachel M. Schmitz, Oklahoma State University, Department of Sociology, 457 Murray Hall, Stillwater, OK 74078

Phone: (405) 744-6105. E-mail: rachel.schmitz@ okstate.edu

Funding: This research was funded by the College of Arts and Sciences at Oklahoma State University.

Acknowledgment: The authors dedicate this work to the vibrant young adults who graciously shared their experiences to make this research a reality. We would also like to thank the anonymous reviewers and Dr. Brandon Andrew Robinson for their supportive feedback in improving the manuscript and helping it reach its full potential.

APA citation: Schmitz, R. M., \& Charak, R. (2020). "I Went into This as One Person, and Then Came Out a Totally Different Person": Native LGBTQ2S+ young adults' conceptions of trauma. Journal of Interpersonal Violence. Advance online publication. doi. doi.10.1177/08862 


\begin{abstract}
Intersecting sources of stigma influence harmful mental health outcomes for lesbian, gay, bisexual, transgender, queer, and Two-Spirit (LGBTQ2S+) young adults (YA) of color as they must manage multiple oppressions. Experiencing both mental health challenges and victimization, LGBTQ2S+ YA of color struggle with distinctive psychological traumas. There is a critical need to determine how certain groups of LGBTQ2S+ YA of color's marginalized social statuses shape trauma understandings. Native LGBTQ2S+ people in general endure diverse forms of oppression and trauma, such as histories of colonialism, contemporary racism, sexism, homophobia, and classism. Understanding the subjective interpretations of violence and trauma among Native LGBTQ2S+ YA is needed to best meet their mental health needs. Through indepth interviews with 13 Native LGBTQ2S+ YA between 18-24 years old, this study delineates processes of how an underrepresented, underserved group of rurally embedded YA conceptualize violent and traumatic life experiences within the context of their mental health. First, participants described their traumatic experiences as shaping persistent harmful mental health outcomes throughout their lives. Secondly, YA conceptualized trauma as pivotal moments that were profound and influential in their significance as a turning point in their lives. Finally, young adults underscored multiple traumas as cumulative and complex in how they interacted to create distinctively harmful mental health challenges. Expansive conceptualizations of trauma can better inform understandings of trauma etiology and promote inclusive health services.
\end{abstract}




\section{'I Went into This as One Person, and Then Came Out a Totally Different Person': Native LGBTQ2S+ Young Adults' Conceptions of Trauma}

The number of young adults (YA) identifying as lesbian, gay, bisexual, transgender, queer, and Two-Spirit (LGBTQ2S+) in the United States is growing, with approximately 8.2\% of millennials adopting expansive gender and sexual identities (Newport, 2018). Stigmatizing structural and interpersonal ideologies continue to shape experiences of prejudice and discrimination among queer people, including heterosexism, cissexism, racism, and adultism directed towards LGBTQ2S+ people (Hatzenbuehler, 2017; Kuper et al., 2014). Stigmatizing social contexts can significantly harm LGBTQ2S+ YA's health through depression (Mustanski et al., 2010) and three times greater likelihood of suicide ideation compared to non-LGBTQ2S+ youth (Marshal et al., 2011) and these outcomes are often worse for LGBTQ2S+ YA of color due to the layering of oppressions, including racism (Schmitz et al., 2020; Toomey et al., 2017).

LGBTQ2S+ YA also endure disproportionately higher rates of interpersonal trauma (i.e., child abuse, intimate partner violence) tied to sources of oppressions including physical (45.2\%) and sexual victimization (16.9\%), and queer YA of color's odds of physical victimization are two to four times higher than Whites (Whitton et al., 2019). At the intersection of experiencing mental health challenges and violence, LGBTQ2S+ YA may also struggle with psychological trauma, such as Posttraumatic Stress Disorder (PTSD), that can harm their long-term development (Charak et al., 2019b; Cook et al., 2017). The Diagnostic and Statistical Manual of Mental Disorders (DSM-5) defines trauma as "actual or threatened death, serious injury, or sexual violence” (p. 271, American Psychiatric Association [APA], 2013). Exposure to multiple traumatic events, especially during childhood, is known as complex trauma (van der Kolk, 2017). 
Quantitative studies have well-documented the adverse mental health effects of trauma (Charak et al., 2019a; Livingston et al., 2019) among LGBTQ2S+ people (Brown \& Pantalone, 2011) and people of color (Bryant-Davis \& Ocampo, 2005). There is a critical public health need, however, to determine how certain LGBTQ2S+ YA of color's experiences of multiple marginalization may shape trauma understandings. Qualitative approaches could help bridge this gap by examining the diverse, subjective mental health needs of LGBTQ2S+YA of color subgroups. Indigenous people who sustain historical trauma, persistent oppressions, and concomitant negative health outcomes often have individualized trauma understandings (Brave Heart et al., 2011). Exposure to complex trauma becomes more salient for multiple marginalized people, such as Native1-identified Two-Spirit2/LGBTQ+ (LGBTQ2S+) people, who experience diverse identity-related oppression and trauma, such as histories of colonialism, racism, sexism, homophobia, classism, and the ensuing health harms (Balsam et al., 2004; Lehavot et al., 2009). For example, Native LGBTQ2S+ people enduring more discrimination have higher odds of harmful behavioral health practices, such as potentially unsafe sexual behaviors (Town et al., 2018) and smoking (Johnson-Jennings et al., 2014), thus demonstrating the linkage between multiple marginalization and adverse health. It is unclear, however, how Native LGBTQ2S+ young people experience violence, trauma, and mental health when they are both struggling to meet ideals of adulthood and managing multiple oppressions. Through in-depth interviews with 13 Native LGBTQ2S+ YA (18-24), the present study delineates the qualitative processes of how a group of multiple marginalized YA conceptualizes traumatic life events. This study can illuminate the distinctive experiences of Native LGBTQ2S+YA in predominantly rural, underrepresented, and underserved regions characterized by social conservatism, which can improve cultural and clinical competencies of health and trauma service providers. 


\section{Background}

\section{LGBTQ2S+ Young Adults and Mental Health}

LGBTQ2S+ YA must often manage experiences of minority stress, where their marginalized sexual and/or gender identities are societally subordinated and pathologized, resulting in significant mental health challenges (Baams et al., 2015; Meyer, 1995). Studies also indicate that LGBTQ2S+ YA are at heightened risk of exposure to childhood abuse and neglect, and intimate partner violence in adulthood compared to their heterosexual counterparts (Charak et al., 2019b). Adverse childhood experiences (ACES), including physical, emotional, and sexual abuse, neglect, household substance use, and family incarceration, can cumulatively harm developmental processes to increase mental health struggles in later life (Chapman et al., 2004; Charak et al., 2019a; Messman-Moore \& long, 2003). This pattern of LGBTQ2S+ YA's experiences of minority stress is in line with the cumulative risk hypothesis, which states that exposure to different types of traumatic events accumulate over time and from multiple varying sources to have a negative effect on an individual's well-being (O’Donnell et al., 2017).

An intersectional lens is necessary for understanding health disparities as people's multiple marginalized identities interact to create distinctively unequal experiences and individuals must often simultaneously manage numerous oppressions (Collins, 1990; Crenshaw, 1990; Meyer, 2010), as sexual and gender minority adolescents experience childhood adversities at higher rates than their heterosexual peers (Sterzing et al., 2017). LGBTQ2S+ YA of color often contend with both LGBT-related and racial-ethnic-related stressors on a regular basis, such as family rejection and police harassment (Kuper et al., 2014). Specifically, Native queer youth report significantly higher odds of mental health challenges like self-harm and sadness compared to White youth (Bostwick et al., 2014); however, the subjective, diverse interpretations of 
violence and trauma among Native LGBTQ2S+ YA have yet to be fully explored. Indeed, an intersectional minority health perspective can help illuminate the distinctive ways various groups of LGBTQ2S+ young adults of color subjectively conceptualize and manage the stigmas they encounter hinging on their multiple marginalized identities (Schmitz et al., 2020).

\section{Marginalized Populations and Trauma}

Stressful life experiences among marginalized groups are highly influential in shaping people's outcomes, particularly across their life course in the development of traumatic stress reactions. Scholars and practitioners generally define trauma as contextual and interpersonal threats to individual well-being. However, traumatic experiences can take on distinctive meanings in people's lives based on their unique interpretations of stress and individual marginalized social statuses (Park \& Gutierrez, 2012). For example, anti-LGBTQ2S+ legislation and political campaigns can have long-lasting traumatic impacts on queer people as they must endure repeated, cumulative disempowerment and disenfranchisement (Russell et al., 2011). The transmission of multiple forms of intergenerational violence and structural oppressions, such as poverty and institutional abuses, can also create long-lasting and significant experiences of trauma among American Indian and Alaska Native youth and families (Willmon-Haque \& BigFoot, 2008). In particular, historical trauma, or how past oppressive events are experienced by marginalized groups (i.e., forced assimilation, genocidal legislation), can adversely affect people's present-day health, such as Native populations continuing to struggle with racism and structural inequalities (Brave Heart et al., 2011; Evans-Campbell, 2008; Mohatt et al., 2014).

People's understandings of their traumatic experiences are largely influenced by their marginalized social statuses, such as being LGBTQ2S+, of color, and young adults. For example, one study found that sexual minority youth in the foster care system were much more 
likely to not only experience sexual abuse, but also endorse more trauma-related beliefs compared to their heterosexual counterparts (Mitchell et al., 2015). Concerning race and ethnicity, American Indian and Alaska Native young adults endure a disproportionate burden of mental health challenges, particularly suicide, compared to their non-Native peers, which has been linked to their elevated exposure to violence and trauma (Goodkind et al., 2010). Native youth are also significantly more likely to engage in early substance use behaviors stemming from discriminatory experiences (Whitbeck et al., 2001). Among a sample of Native youth in substance abuse treatment, participants reported an average of four lifetime traumas, and 14\% experienced PTSD (Deters et al., 2006). These varied experiences of trauma among distinctive marginalized groups of YA underscores the need to examine diverse trauma interpretations, particularly when individuals must navigate multiple axes of oppression simultaneously.

An intersectional approach is also effective in more holistically understanding experiences of trauma as they interact with people's multiple, diverse identities (Baird et al., 2019). When compared to their Native heterosexual peers, Native LGBTQ2S+ people experience more childhood physical abuse and familial historical trauma, highlighting the role of multiple marginalization (Balsam et al., 2004). One study demonstrated the power of historical trauma in that Native LGBTQ2S+ individuals who had attended compulsory, White-centered assimilationist boarding schools struggled more with anxiety, PTSD, and suicide ideation (Evans-Campbell et al., 2012). Additionally, the epidemic of physical and sexual violence perpetrated against American Indian and Alaska Native women is further heightened among sexual minorities, as in one study where $85 \%$ reported sexual assault and $78 \%$ reported physical assault (Lehavot et al., 2009). While it is evident that individuals at the intersection of being Native and LGBTQ2S+ undergo distinctive challenges with mental health and trauma, young 
adulthood must also be examined as this developmental period is fraught with uncertainty and stigma. Therefore, we expand conceptualizations of trauma by elevating the narratives of an underrepresented group, Native LGBTQ2S+ young adults, to illuminate how the intersections of age, race, ethnicity, gender, and sexuality shape their traumatic experiences and mental health.

\section{Method}

The present study was conducted in 2018 through 2019 in Oklahoma. To be eligible, participants had to be in the age range of 18 and 25 years, and self-identify as lesbian, gay, bisexual, transgender, queer, Two-Spirit, or another expansive gender and/or sexual identity (including some who identified as asexual). Additionally, young people had to subjectively selfidentify at least one component of their racial and ethnic identity as Native American or American Indian. We recruited young adults through college listservs, flyers posted in community and campus public areas, and social media networks through regional social service organizations (SSOs) supporting the study. The project was advertised as a "research study, 'Strength of Spirit,' which explores Native LGBTQ2S+ young adults' understandings of trauma and mental health.” Interested potential participants contacted the first author over email to discuss the study, were asked five screening questions to determine eligibility (e.g., age, gender, sexuality, Native identity, tribal affiliation), and if eligible, the first author and participant set up a time to conduct the interview. The first author answered all questions and concerns both potential and eligible participants had regarding the study. We also utilized snowball sampling by handing out optional referral cards with the study contact information to all participants.

To promote cultural humility within our study design (Yeager \& Bauer-Wu, 2013), we drew from the expertise of an informal community advisory board (CAB) consisting of service providers and researchers who directly served Native LGBTQ2S+ individuals. Of the five 
members of the $\mathrm{CAB}$, three identified as Native with varied tribal memberships. The $\mathrm{CAB}$ provided ongoing support of the study protocol, as well as data collection and analysis, such as by suggesting language revisions of capitalizing "Two-Spirit" and offering mental health resources to study participants. The study was advertised in multiple rurally embedded communities across Oklahoma (i.e., networks of both campus affiliations and Native and LGBTQ2S+-serving SSOs), which reached young adults from a variety of regional backgrounds with strong rural ties and multiple different tribal affiliations. Young adults in the final sample represented a mixture of both university and wider community populations, as participants reported hearing about the study from a variety of sources, including flyers and social media posts. The study received institutional review board (IRB) approval from the lead author's institution, where it was specifically assessed by the Native/Indigenous IRB content expert.

\section{Procedure}

The first author conducted all the interviews in English. Study participants completed one tape-recorded, in-depth face-to-face interview lasting approximately one hour and a short demographic questionnaire. Participants were interviewed in private locations, such as a university office or a reserved library study room. Study procedures were explained to participants and informed consent was obtained prior to the interview. Participants received a \$20 gift card in exchange for their time. The first author asked all participants the same set of 12 open-ended questions related to their LGBTQ2S+ identities, mental health challenges, and understandings of trauma. Primary interview questions included (see Appendix for full interview guide): How do you define the word "trauma"? What have you experienced in your life that has caused you a lot of stress? How have you dealt with trauma in your life? What role have your identities played in your experiences of stress and/or trauma? We utilized a constructivist 
approach in the development and implementation of this study (Guba \& Lincoln, 1994), by promoting "inclusion-centered interpretations" in the recruitment materials, interview protocol, and coding strategy to elevate Native LGBTQ2S+ subjective, individualized understandings of trauma (Choo \& Ferree, 2010). Participants identified their own pseudonyms to ensure respondent confidentiality.

The first and second authors collaborated to code and analyze the data using MAXQDA 2018, such as through iterative memoing of coding processes and collaborative discussions of theme construction to enhance the study's rigor and trustworthiness (Creswell \& Miller, 2000). As a gender-conforming, white woman academic whose sexual identity was unknown to participants, the interviewer and primary coder remained cognizant of how her positions of social privilege influenced the interviewing dynamics and data interpretations working with Native LGBTQ2S+ young adults with trauma histories. For example, the first author decentered her own biases and worldview during interviews and data analysis to more effectively act as a conduit for uplifting marginalized young people's perspectives (Levy, 2013). Furthermore, the second author regularly reflected on how her identities of being a gender-conforming, South Asian woman academic shaped her interpretations of participants' narratives.

To holistically capture participants' diverse lived experiences from their own perspectives, we utilized narrative inquiry to analyze the themes that emerged from young people's stories (Chase, 2005). First, we employed initial coding to identify emergent themes surrounding subjective definitions of trauma and personal traumatic experiences (Saldaña, 2015). Next, we engaged focused coding to highlight young adults' lived realities through the lens of their own intersectional interpretations of their experiences to see how participants' experiences and understandings of trauma were interrelated with their identities and mental health. As an 
example, we combined the initial codes of "trauma as lifelong" and "childhood-based trauma" into the more focused code related to young people's understandings of "managing trauma as a continual process." Through this coding procedure, the final themes emerged inductively from the data using a thematic analytic approach to confirm the themes that followed validated strategies. For example, we continually reviewed the emergent data throughout the coding process to ensure sufficient evidence for each theme present in the data as whole and we also constructed concept maps to visually delineate relationships and connections among the codes comprising each theme (Daley, 2004; Nowell et al., 2017). The combination of initial and focused coding supports a narrative constructivist perspective, which underscores participants' authority over their own lived experiences and the meanings they construct to understand their lives (Franzosi, 1998; Saldaña, 2015). In the event of coding disagreements, we discussed the source of conflict and then reanalyzed data segments through modifying codes or identifying disconfirming evidence.

We also offered participants the option of being recontacted via email to review the data once data collection was complete as a way to enhance the rigor and credibility of the findings. Of all participants contacted, eight young adults (67\%) engaged in member checking by providing feedback on emerging codebooks and the deidentified raw data (Creswell \& Miller, 2000). Overall, participants' comments and suggestions reflected the researchers' interpretations of the data and assigned codes. In some cases, participants requested revisions to their narrative to more accurately reflect their intended meaning, such as replacing the word "victim" with "survivor" to promote an empowered perspective. We acknowledge the reality that both our varying social positionality as researchers and the advisory role of the CAB members shaped our interpretations of the findings, and member checking was employed to mitigate potential implicit 
biases. Through these multiple validating strategies of rigorous coding and member checking, we achieved data saturation in that conceptualizations of trauma across participants began to reveal a similar pattern at the initial coding of the eighth interview, and by the thirteenth interview, no novel, distinctive understandings emerged through narrative inquiry (Fusch \& Ness, 2015) and thematic analysis (Nowell et al., 2017). This approach also adheres to sampling principles wherein additional data points beyond the required may be considered a burden on research parties, particularly when the population of interest is largely homogeneous (i.e., identifying as Native LGBTQ2S+ YA) (Guest et al., 2006).

\section{Findings}

Young adult participants were between 18 and 24 years old, and on average they were 20 years old. Descriptive statistics of our analytic sample can be found in Table 1.

\section{TABLE 1 ABOUT HERE}

The qualitative findings revealed the multiple diverse ways Native LGBTQ2S+ young adults conceptualized the interrelated experiences of mental health stressors (e.g., anxiety, depression) and traumatic processes based on their distinctive life experiences. First, participants emphasized how trauma was enduring in that it continued to negatively impact young people's lives after they had first experienced, which involved persistent harmful mental health outcomes. Secondly, trauma was also conceptualized as comprising distinctive, foundational moments that were profound in their significance as a turning point in young people's lives. Finally, young adults also underscored trauma as intersecting with oppressions across their multiple marginalized identities of age, race, ethnicity, gender, and sexuality, and that traumatic effects were cumulative in how they compounded to create distinctively harmful mental health challenges. These findings emphasize the importance of centering Native LGBTQ2S+ young 
people's narratives of trauma histories to develop more inclusive, intersectional definitions of trauma and its manifestations. All young adult participants reported experiencing trauma in some way, and the following conceptualizations of trauma represent an overview of young people's experiences. Young adults' interpretations of trauma, however, are not mutually exclusive as participants often understood their interpersonal trauma as complex, in that it varied by form and spanned multiple types. Because we aim to make our findings concretely applicable for health interventions and services tailored for Native LGBTQ2S+ young adults, we follow validated strategies calling for practical utility in the presentation of qualitative research findings by pairing participant narratives alongside analytic interpretations (Sandelowski \& Leeman, 2012). “As I got older, I realized what was actually happening and put pieces together": Processing

\section{Trauma and its Enduring Harmful Effects}

Although all participants reported experiencing trauma in some shape or form, many Native LGBTQ2S+ young adults underscored how their conceptualization of trauma often occurred in retrospect once they could process the experience. In this way, young people perceived trauma as having enduring effects that continued to shape their lives in incremental, yet significant ways as they developed into adulthood. For example, Brandon, who identified as Native, White, queer, and gay, discussed the enduring legacy of their father and the realization of how this trauma continued to shape their life as they got older:

My father...he's done really bad things. He was very abusive to my mother when I was younger, almost to the point of hospitalization. As I got older, I realized what was actually happening and put pieces together. All of my anxiety, depression, all of it finally made sense when I really thought about what he did to us. 
In Brandon's case, the realization of trauma occurred over time as Brandon "got older" and began to "put pieces together" through introspection and assessment of their early life experiences by working with mental health counselors to "know how things work and the logistics behind it...so that you know what you can do to help better yourself and heal.” By attributing their father's chronic abuses, particularly in witnessing violence perpetrated by their father on their mother, to their symptoms of anxiety and depression (e.g. feeling isolated, trouble getting enough sleep, considering suicide), Brandon aptly described how trauma can have enduring harmful effects that young adults may not perceive until later in life.

Expanding on the notion of processing trauma and its enduring effects that can cascade across a young person's life, some participants stressed how trauma could take the form of poignant familial rejection that continued to impact them as they emerged into adulthood. Leif's narrative, a Native and Black transgender queer man, encapsulates trauma as the loss of a critical family support system that can repeatedly harm a young person through persistent stressful experiences that, for Leif, began in early childhood:

The most stressful thing about family is their violent ignorance. I don't really talk to either of my parents anymore. There are times, even now, and especially when I was younger, where something would happen at school or with a romantic partner or something, and I'd just be completely lost. I'd think, 'I really want my mom,' and my mom was never really like a mom to me anyway. I don't have a maternal figure, I don't have a paternal figure. I had to teach myself everything.

Leif's parents" "violent ignorance" revolved around the rejection of Leif's expansive gender and sexual identities that conflicted with their more stereotypical, idealized beliefs grounded in conservative Christian ideology. The enduring effects of trauma for young adults 
like Leif, then, can emerge incrementally as they transition through major developmental periods, such as adolescence and young adulthood, on their own without sources of familial support and guidance. Specifically regarding identity-based family rejection experiences and continued exposure, Leif shared, "My parents took me to conversion therapy when I first came out" and so "like summer or winter break, I would always become suicidal without school as an outlet." A young person being forced to "teach myself everything" can potentially lead to experiences of retraumatization as they exert significant labor navigating major milestones in life, such as school experiences and romantic relationships, which can activate stressful trauma memories.

Further reiterating how anti-LGBTQ2S+ familial ideologies can shape enduring traumatic effects influencing young adults' development and mental health, some participants stressed the importance of identity management where they kept their LGBTQ2S+ identity separate from family relationships to avoid potential conflict. This process of navigating enduring trauma can be strategic for young adults if they are continually gauging the risks and benefits of concealing their identity from family members, with the benefit being sustained family relationships at the risk of mental health harms. Alec, a Native and White cisgender bisexual man, described the labor and stressors associated with "debating being bisexual or I wasn't sure if I was gay when I was in ninth grade... and keeping it to myself, I started selfharming." The fear of family rejection can be integral in motivating an LGBTQ2S+ YA to conceal their identities, which can adversely shape mental health, such as in Alec's case: "Whenever I would hear family talk about 'homosexuality is bad,' that really put suicidal thoughts in my head...it caused me to fall into a really bad depression because I was trying to internalize all of these feelings." As YA like Alec described, the trauma of repressing a core 
aspect of one's identity from family can have notable cascading effects for young people as they strive for markers of adulthood, such as relationship formation and identity development. Having to continually hide your identity from close family members requires significant labor and energy that can incrementally harm a young person's mental health. Alec, for example, struggled with wanting "to share my life with them [family]...but of course, if it's a guy, I feel like I have to hide that from them," which was shown to shape feelings of persistent trauma and stress in attempting to balance valued family relationships with the full expression of one's identities. "I went into this as one person, and then came out a totally different person": Trauma as

\section{Turning Points}

In addition to enduring trauma as persistent and incremental through cascading, enduring effects, Native LGBTQ2S+ young adults also conceptualized trauma as discrete pivotal moments that were transformative in shaping their lives in significantly harmful ways. These turning point events did not occur within a vacuum, however, but often interacted with young people's multiple marginalized identities and continued to play a role in how young people managed their mental health struggles. In one such case, Evelyn, a Native cisgender lesbian woman, recounted the formative, life-changing event of extreme parental rejection and fundamental denial of family relationship status that lied at the core of her understanding of trauma:

Trauma for me includes some things I have trouble letting go of, like I wouldn't say are physically harmful, but emotionally just tear me down. Like when I first came out to my parents, my mom was like, 'You're not my daughter anymore.' That kind of trauma.

For young adults like Evelyn, traumatic experiences understood as turning points can have a uniquely harmful influence on their emotional wellbeing as it is tied to their identity development processes, as Evelyn further elaborated that her mother's rejection was a harmful 
turning point in that this trauma "haunts me over and over again, and that I can't seem to fix, or forgive, or get over." Here, Evelyn emphasized a subjective definition of trauma that was not "physically harmful," but rather works to "emotionally just tear me down" in being a pivotal point of trauma in her life that shifted not only her relationship with her mother but also her emotional wellbeing. This finding demonstrates the importance of a holistic approach to wellbeing acknowledging psychological trauma, such as from explicit family rejection.

Profound experiences of trauma described by YA were characterized not only by their effect on individual identity development, but also through the traumatic influence of how interpersonal conflict shaped YA's sense of self and key social relationships. Foundational incidences of trauma for YA were often perceived as being tied to formative social interactions that they describe as being a type of pivotal turning point in their lives. In highlighting how one such traumatic interaction can have irrevocable repercussions from a YA's perspective, Red, a Native and Black cisgender bisexual woman, recounted a damaging exchange with her grandmother that revealed anti-LGBTQ2S+ sentiment:

I went into this as one person, and then came out a totally different person. I was talking to my grandma about gay rights. I came in thinking, "She's always been a loving person to me, so even if she doesn't agree with something, she'll still understand, and it'll be okay." Just hearing her bash it over and over again, while I'm silently saying, “But, I'm this. You're bashing me.” We used to have such a close connection. She was my best friend. And now, I can't stand to be in the same room with her for more than an hour.

In Red's narrative of trauma, a harmful turning point moment can consist of a singular significant event that may seem mundane and inconsequential on the surface, however its lifechanging adverse consequences can be highly salient for a young person navigating multiple 
marginalized identities. These examples of trauma as pivotal moments can be subjectively defining for a young adult, particularly when it can literally shape them into "a totally different person" from their perspective and they must then learn to adapt to various fractured elements in their lives, such as identity development, sense of self, and social relationships.

Concerning key social relationships in young people's lives, the loss of a significant family member can also serve as a pivotal turning point of trauma for a young adult. The abrupt shift in family dynamics that can result from a close family member's death can be challenging for a young person to navigate, especially when they are simultaneously working to manage developmental processes, such as establishing gender and sexual identities. In the words of Alexis, a Native and White cisgender queer woman, trauma is "anything that totally shifts multiple aspects of your life, whether it be the death of a close family member or something like coming out to your parents," which are challenges Alexis had endured throughout adolescence. Alexis described the story of her cousin, who ultimately "died of a drug overdose when I was a sophomore in high school," and how this abrupt loss motivated her to begin seeing a therapist to manage feeling "betrayed is the best word, just because he [cousin] was doing so well and we were finally getting close again." Trauma as a turning point involving the sudden death of a beloved family member can serve as a hinge upon which a young adult is thrust into experiencing mental health challenges, such as Alexis's account of "having anxiety attacks a couple times a week after he passed, which was awful...a lot of them were triggered by his death." This conceptualization of trauma underscores how challenging discrete life events, including family disruption, can certainly interact with pre-existing mental health challenges, as Alexis also discussed having “struggled with depression and self-harm” prior to her cousin's death. 
"I hate myself for everything that happened to me in my childhood": Trauma as Cumulative

Trauma conceptualizations as described by many Native LGBTQ2S+ young adults were also generally understood not as a single event, but rather as a multitude of stressful life experiences that were cumulative in terms of their timing, duration, and impact. In this way, participants often recounted extremely stressful and arduous early childhood experiences that were replete with adverse events such as abuse, neglect, and family instability. Mikele, a Native Two-Spirit young adult, captured the definition of trauma as cumulative in their description of a challenging childhood that consisted of abuse and conflicts with family, religion, and mental health:

My childhood is shot. Me and my sister were the children of divorce. I didn't know it, but we had PTSD our entire childhood. And I was molested like my entire childhood by a man I thought I could trust. He taught me everything he did was for God. So that is probably why I'm kind of struggling with Christianity. I've also struggled with depression and anxiety for a very long time.

Adverse childhood experiences, such as being "children of divorce" and repeated exposure to sexual abuse, can be mutually reinforcing and interacting with one another leading to experiences of complex and harmful struggles with trauma in the most formative developmental periods of life. This was evident in Mikele's narrative as symptoms of PTSD, anxiety, and depression, spanned their early childhood, and continued into young adulthood (e.g., "waking up crying all the time" after vivid nightmares). Mikele summarized how they believed their cumulative childhood trauma impacted their sense of self by saying, "I hate myself for everything that happened to me in my childhood." 
Similar to experiencing highly damaging familial conflict and abuse that intersect throughout a young adult's life, several participants also stressed the integral role that residential family instability played in shaping their understanding of trauma. In Leighann's narrative, a Native and Black cisgender bisexual woman, the layering of trauma from infancy to early adolescence multiplied to create early childhood histories of unstable housing and caregiving situations:

I was born while my mom was in prison. I went home with my aunt, who I now call mom. The other one just kind of gave birth to me. But, throughout my entire childhood up until I was 11, it was just between those two houses. Because my biological mother would keep going back to jail, then she'd come out, she'd swear she was fine, and she'd take me, and it would just keep repeating.

Here again, YA viewed the source of their trauma as stemming from family conflict where nurturance and stability were largely absent when YA felt they were at the mercy of caregivers. For Leighann, who lacked "any good memories of my biological mom," the resulting mental health challenges from complex childhood trauma manifested in high school when "I started acting out, and skipping class, and just kind of not caring about anything." As indicated in these examples, experiencing multiple traumas in a young person's early life can often impose the burden of significant mental health struggles, such that YA described symptoms of conduct disorder and delinquent behavior.

From participants' narratives, family conflict can take on many forms in YA's lives, and abuse and neglect from trusted caregivers can have the cumulative effect of not only harming a young person's physical health, but also their mental and emotional wellbeing when they feel powerless and stripped of autonomy. Participants often articulated the nuanced ways that family- 
based trauma was incredibly damaging to their sense of autonomy and humanity, and these experiences largely accumulated across a young adult's most formative years. The narrative of Flora, a Native and White transgender asexual woman, is poignant in its emphasis on how the cumulative trauma of familial abuses and indifference took a significant toll on Flora's sense of personhood:

The fact that someone would want to strip you of all control. It's like not consider you a person, just an object that they can destroy, or abuse at their own will, and you've got nothing to say about it. Like a lot of bullying and harassment from peers. Also, family, like my brother in particular, would often try to physically harm me, even kill me, at times. It was jarring because my family would always excuse it.

For YA like Flora, traumatic experiences from family sources spanned both severe physical abuse as well as significant supervisory neglect stemming from her caregiver's refusal to intervene and ensure Flora's safety. The cumulative effects of complex trauma, including physical and psychological victimization, and neglect, can therefore have extreme adverse consequences for marginalized young adults in the form of feeling dehumanized and "strip[ped] of all control."

\section{Discussion}

Providing evidence for the cumulative risk hypothesis (O’Donnell et al., 2017), the present study findings underscore the importance of expanding definitions of trauma to better encompass the diverse backgrounds and lived experiences of multiple marginalized individuals, particularly Native LGBTQ2S+ young adults. Primarily, our empirical focus elevating marginalized young people's individualized understandings of traumatic experiences is essential in promoting more nuanced conceptions of trauma to address enduring inequalities across health, 
social supports, and structural opportunities. Participants framed their exposure to trauma using three overarching themes that embodied the varied processes of how trauma can occur and the dynamic ways it can influence young adults, and many participants fell into multiple themes, so they were not mutually exclusive. The theme of processing trauma as enduring harmful effects was salient for young adults in that processing early trauma experiences could be retraumatizing as the adverse mental health outcomes persisted across young adulthood and often became chronic issues. Relatedly, trauma as turning points consisted of poignant, life-changing events that served to traumatize young adults in their formative effect of being a source of long-term mental health challenges such as symptoms of anxiety and depression. Finally, experiences of trauma as cumulative characterized participants' trauma conceptualizations as young adults often endured multiple, interactive experiences that stacked to shape increasingly challenging mental health outcomes. Taken together, the present study advances key research surrounding the dynamics of complex trauma in the lives of marginalized people to foreground developing more expansive, inclusive definitions of traumatic experiences and meanings (Brave Heart et al., 2011; Mohatt et al., 2014). Furthermore, this study's findings are especially notable in acknowledging the power of Native LGBTQ2S+ young adults' authority as experts in understanding their own personal trauma and mental health challenges.

The enduring harmful effects of trauma narrated by study participants complements the additive/cumulative risk model of trauma in that the mental health struggles people endure as a result of exposure to multiple traumatic events do not have a discrete end point, but rather that harmful effects can be short-term or span across life (O’Donnell et al., 2017). For multiple marginalized people, in particular Native LGBTQ2S+ young adults, the cascading effects of trauma can shape significant health vulnerabilities through the potential for revictimization 
depending on the type of trauma endured. For example, experiences of severe caregiver and family rejection at an early age can heighten young adults' potential for revictimization from an opportunistic perpetrator in the absence of caregiver guidance and support, leaving the young person with a constrained safety net on which to rely (Charak et al., 2019a, 2019b; MessmanMoore \& Long, 2003). Familial rejection can have distinctively harmful traumatic impacts on Native LGBTQ2S+ young adults that can extend throughout their lives in the form of persistent experiences of prejudice and discrimination tied to their racial, ethnic, gender, and sexual identities (Schmitz et al., 2020). Mental health challenges stemming from family-related trauma may create barriers to young people's successful transition into adulthood where they face expectations of being independent and self-sufficient (Chapman et al., 2004).

Past research into understanding diverse forms of trauma has tended to reinforce a hierarchy of positioning certain overt forms of trauma, such as childhood physical and sexual abuse, as more harmful than trauma involving psychological and emotional abuses (Lau et al., 2005). Our study findings, however, challenge this framework by underscoring the impact of pivotal moments of psychological and emotional trauma that can be enacted through dominant interpersonal relationships in a young adult's life and can take on diverse forms (e.g., caregiver rejection; death of a family member). In particular, damaging social interactions with a trusted person can be especially harmful for a young adult's mental health when these problematic interactions revolve around the derogation of youth's gender and/or sexual identity (Ryan et al., 2010). Severe childhood emotional and psychological abuse from influential caregivers and family members is associated with social withdrawal and lower socioemotional competencies during adolescence (Shaffer et al., 2009). Caregiver abuse can also be especially harmful for LGBTQ2S+ young people transitioning into adulthood as they often struggle to balance 
maintaining instrumental supports with navigating their identities during a formative period of personal development (Schmitz \& Tyler, 2018). Therefore, as many participants were full-time college students, the present study's findings can be especially informative for establishing more inclusive campus programming to support the mental health of Native LGBTQ2S+ YA.

Perceptions and interpretations of trauma are also complex in that they can span multiple aspects of young adults' lives, including their marginalized identities and life experiences, which results in a layering effect where traumatic events stack together to create increasingly challenging mental health struggles. Trauma does not often occur in a singular, simplistic form, but rather can take the shape of numerous adverse events, such as unstable housing, familial abuse, and supervisory neglect, that occur either concurrently or in close succession throughout a young adult's early life. These findings align with research on polyvictimization, or how young children can endure numerous different types of victimization in a brief time period that cluster together and create significantly higher likelihood for developing trauma symptomology (Charak et al., 2019c; Finkelhor et al., 2007). Additionally, multiple marginalized groups like Native LGBTQ2S+ young adults must often manage their intersecting identities in the face of prejudice and discrimination, which can also impact the layering of trauma in their lives to include antiLGBTQ2S+ sentiment, racism, and histories of colonialism (Balsam et al., 2004; Lehavot et al., 2009). The layering of trauma hinging on young adults' multiple victimization experiences as well as their marginalized identities underscores the need for holistic, individualized conceptions of trauma that more comprehensively capture the scope of their diverse life struggles and individualized trauma histories (van der Kolk, 2017).

\section{Limitations}


This study provides key insight into the distinctive understandings and experiences of trauma among Native LGBTQ2S+ young adults, yet important limitations must be considered in guiding future research. Highlighting the rich diversity of Native populations currently residing in the United States, we do not aim to generalize our findings to all young adults who identify as both Native (and its expansive terminology) and LGBTQ2S+. We acknowledge that there is likely great variation in trauma definitions and experiences for Native peoples depending on their tribal affiliation, regional context (e.g. reservations), individual identity, and phenotypical perceptions of idealized Native presentations (McKay, 2019). Therefore, future research should explore how young adults' trauma understandings vary across specific tribal affiliations and memberships, which could facilitate tribal health service collaborations and interventions. Although the present study underscores the need for more expansive definitions of trauma to encapsulate multiple marginalized people's lived experiences, our findings are limited by participants' ability to recall past traumatic events. People's retrospective memory capacity may indeed be flawed because of the stress-inducing nature of trauma (Lalande \& Bonanno, 2011), so additional studies could complement the present findings through real-time data collection, such as diary studies or ecological momentary assessment (EMA) among marginalized populations. The present study comprised a community sample of LGBTQ2S+ YA and their narrated mental health symptomology may not fit the DSM-5 criteria for a mental disorder (APA, 2013). To gauge standardized measures' clinical significance, future studies should interview clinical samples of LGBTQ2S+ YA or embed screening questionnaires measuring mental health outcomes (e.g., Patient Health Questionnaire-9 measuring depressive symptoms) as part of a mixed methods approach. Nonetheless, it is essential to consider every account of trauma described by individuals to understand their unique experiences and related consequences. 


\section{Conclusion}

In expanding conceptualizations of trauma grounded in Native LGBTQ2S+ young adults' narratives, our study has significant implications for both improving services and expanding policies to support marginalized young people's well-being. Our findings shed light on acknowledging the multiple marginalization young adults can endure and how this may correspond with their complex trauma experiences that are not static, but rather dynamic in their scope and adverse effects. Health service providers can play a key role in (re)affirming young adults' identities, particularly when they have complex trauma histories and are navigating intersecting oppressions related to their gender, sexual, racial, and ethnic identities (Schmitz \& Tabler, 2019). Trauma-informed health resources, which require providers to be actively, continually responsive to patients' diverse needs and experiences with victimization, are especially critical in promoting the healing process and potential resilience among LGBTQ2S+ people of color (Singh, 2017). Elevating issues faced by Native LGBTQ2S+ populations within mainstream awareness can promote public health campaigns to both validate marginalized groups' multiple identities (Walters et al., 2006) and address the epidemic of violence endured by Native populations (Lehavot et al., 2009). Native LGBTQ2S+ young adults' trauma narratives in this study exemplify the importance of both actively listening and responding to marginalized perspectives in efforts to promote expansive understandings of trauma that challenge dominant, oppressive forces. 


\section{References}

American Psychiatric Association (APA). (2013). Diagnostic and statistical manual of mental disorders (5th Ed.). Author.

Balsam, K. F., Huang, B., Fieland, K. C., Simoni, J. M., \& Walters, K. L. (2004). Culture, trauma, and wellness: A comparison of heterosexual and lesbian, gay, bisexual, and twospirit Native Americans. Cultural Diversity and Ethnic Minority Psychology, 10, 287301.

Baams, L., Grossman, A. H., \& Russell, S. T. (2015). Minority stress and mechanisms of risk for depression and suicidal ideation among lesbian, gay, and bisexual youth. Developmental Psychology, 51, 688-696.

Baird, S. L., Alaggia, R., \& Jenney, A. (2019). “Like Opening Up Old Wounds”: Conceptualizing intersectional trauma among survivors of intimate partner violence. Journal of Interpersonal Violence, Advance online publication. https://doi.org/10.1177/0886260519848788

Bostwick, W. B., Meyer, I., Aranda, F., Russell, S., Hughes, T., Birkett, M., \& Mustanski, B. (2014). Mental health and suicidality among racially/ethnically diverse sexual minority youths. American Journal of Public Health, 104, 1129-1136.

Brave Heart, M. Y. H., Chase, J., Elkins, J., \& Altschul, D. B. (2011). Historical trauma among indigenous peoples of the Americas: Concepts, research, and clinical considerations. Journal of Psychoactive Drugs, 43, 282-290.

Brown, L. S., \& Pantalone, D. (2011). Lesbian, gay, bisexual, and transgender issues in trauma psychology: A topic comes out of the closet. Traumatology, 17, 1-3. 
Bryant-Davis, T., \& Ocampo, C. (2005). The trauma of racism: Implications for counseling, research, and education. The Counseling Psychologist, 33, 574-578.

Burton, C. M., Marshal, M. P., Chisolm, D. J., Sucato, G. S., \& Friedman, M. S. (2013). Sexual minority-related victimization as a mediator of mental health disparities in sexual minority youth: A longitudinal analysis. Journal of Youth and Adolescence, 42, 394-402.

Chapman, D. P., Whitfield, C. L., Felitti, V. J., Dube, S. R., Edwards, V. J., \& Anda, R. F. (2004). Adverse childhood experiences and the risk of depressive disorders in adulthood. Journal of affective disorders, 82, 217-225.

Charak, R., Eshelman, L. R., \& Messman-Moore, T. L. (2019a). Latent classes of childhood maltreatment, adult sexual assault, and revictimization in men: Differences in masculinity, anger, and substance use. Psychology of Men and Masculinity, 20, 503-514.

Charak, R., Villarreal, L., Schmitz, R. M., Hirai, M., \& Ford, J. D. (2019b). Patterns of childhood maltreatment and intimate partner violence, emotion dysregulation, and mental health symptoms among lesbian, gay, and bisexual emerging adults: a three-step latent class approach. Child Abuse \& Neglect, 89, 99-110.

Charak, R., Ford, J. D., Modrowski, C. A., \& Kerig, P. K. (2019c). Polyvictimization, emotion dysregulation, symptoms of posttraumatic stress disorder, and behavioral health problems among justice-involved youth: A latent class analysis. Journal of Abnormal Child Psychology, 47, 287-298. doi.org/10.1007/s10802-018-0431-9

Chase, S. E. (2005). Narrative inquiry: Multiple lenses, approaches, voices. In N. K. Denzin \& Y. Lincoln (Eds.), The SAGE Handbook of Qualitative Research (3rd ed., pp. 651-679). Sage. 
Choo, H. Y., \& Ferree, M. M. (2010). Practicing intersectionality in sociological research: A critical analysis of inclusions, interactions, and institutions in the study of inequalities. Sociological Theory, 28, 129-149.

Collins, P. H. (1990). Black feminist thought: Knowledge, consciousness, and the politics of empowerment. Routledge.

Cook, A., Spinazzola, J., Ford, J., Lanktree, C., Blaustein, M., Cloitre, M., ... \& Mallah, K. (2017). Complex trauma in children and adolescents. Psychiatric Annals, 35, 390-398.

Crenshaw, K. (1990). Mapping the margins: Intersectionality, identity politics, and violence against women of color. Stanford Law Review, 43, 1241.

Creswell, J. W., \& Poth, C. N. (2017). Qualitative inquiry and research design: Choosing among five approaches. Sage.

Creswell, J. W., \& Miller, D. L. (2000). Determining validity in qualitative inquiry. Theory into Practice, 39, 124-130.

Daley, B. J. (2004). Using concept maps in qualitative research. In A. J. Cañas, J. D. Novak, F. M. González (Eds.), Concept Maps: Theory, Methodology, Technology (pp. 191-197). Proceedings of the First International Conference on Concept Mapping.

Deters, P. B., Novins, D. K., Fickenscher, A., \& Beals, J. (2006). Trauma and posttraumatic stress disorder symptomatology: Patterns among American Indian adolescents in substance abuse treatment. American Journal of Orthopsychiatry, 76, 335-345.

Evans-Campbell, T. (2008). Historical trauma in American Indian/Native Alaska communities: A multilevel framework for exploring impacts on individuals, families, and communities. Journal of Interpersonal Violence, 23, 316-338. 
Finkelhor, D., Ormrod, R. K., \& Turner, H. A. (2007). Poly-victimization: A neglected component in child victimization. Child Abuse \& Neglect, 31, 7-26.

Franzosi, R. (1998). Narrative analysis — or why (and how) sociologists should be interested in narrative. Annual Review of Sociology, 24, 517-554.

Fusch, P. I., \& Ness, L. R. (2015). Are we there yet? Data saturation in qualitative research. The Qualitative Report, 20, 1408-1416.

Goodkind, J. R., Ross-Toledo, K., John, S., Hall, J. L., Ross, L., Freeland, L., ... \& Lee, C. (2010). Promoting healing and restoring trust: Policy recommendations for improving behavioral health care for American Indian/Alaska Native adolescents. American Journal of Community Psychology, 46, 386-394.

Guba, E. G., \& Lincoln, Y. S. (1994). Competing paradigms in qualitative research. In N. K. Denzin \& Y. S. Lincoln (Eds.), Handbook of qualitative research (pp. 105-117). Sage.

Guest, G., Bunce, A., \& Johnson, L. (2006). How many interviews are enough? An experiment with data saturation and variability. Field methods, 18, 59-82.

Hatzenbuehler, M. L. (2017). Advancing research on structural stigma and sexual orientation disparities in mental health among youth. Journal of Clinical Child \& Adolescent Psychology, 46, 463-475.

Johnson-Jennings, M. D., Belcourt, A., Town, M., Walls, M. L., \& Walters, K. L. (2014). Racial discrimination's influence on smoking rates among American Indian Alaska Native twospirit individuals: does pain play a role? Journal of Health Care for the Poor and Underserved, 25, 1667-1678. 
Kuper, L. E., Coleman, B. R., \& Mustanski, B. S. (2014). Coping with LGBT and racial-ethnicrelated stressors: A mixed-methods study of LGBT youth of color. Journal of Research on Adolescence, 24, 703-719.

Lalande, K. M., \& Bonanno, G. A. (2011). Retrospective memory bias for the frequency of potentially traumatic events: A prospective study. Psychological Trauma: Theory, Research, Practice, and Policy, 3, 165-170.

Lau, A.S., Leeb, R.T., English, D., Graham, J. C., Briggs, E. C., Brody, K. E., Marshall, J. M. (2005) What's in a name? A comparison of methods for classifying predominant type of maltreatment. Child Abuse \& Neglect, 29, 533-551.

Lehavot, K., Walters, K. L., \& Simoni, J. M. (2009). Abuse, mastery, and health among lesbian, bisexual, and two-spirit American Indian and Alaska Native women. Cultural Diversity and Ethnic Minority Psychology, 15, 275-284.

Levy, D. L. (2013). On the outside looking in? The experience of being a straight, cisgender qualitative researcher. Journal of Gay \& Lesbian Social Services, 25, 197-209.

Livingston, N. A., Berke, D. S., Ruben, M. A., Matza, A. R., \& Shipherd, J. C. (2019). Experiences of trauma, discrimination, microaggressions, and minority stress among trauma-exposed LGBT veterans: Unexpected findings and unresolved service gaps. Psychological Trauma: Theory, Research, Practice, and Policy, 11, 695-703.

Marshal, M. P., Dietz, L. J., Friedman, M. S., Stall, R., Smith, H. A., McGinley, J., ... \& Brent, D. A. (2011). Suicidality and depression disparities between sexual minority and heterosexual youth: A meta-analytic review. Journal of Adolescent Health, 49, 115-123.

McKay, D. L. (2019). Real Indians: Policing or protecting authentic indigenous identity? Sociology of Race and Ethnicity, 2332649218821450. 
Messman-Moore, T. L., \& Long, P. J. (2003). The role of childhood sexual abuse sequelae in the sexual revictimization of women: An empirical review and theoretical reformulation. Clinical Psychology Review, 23, 537-571.

Meyer, I. H. (1995). Minority stress and mental health in gay men. Journal of Health and Social Behavior, 36, 38-56.

Meyer, I. H. (2010). Identity, stress, and resilience in lesbians, gay men, and bisexuals of color. The Counseling Psychologist, 38, 442-454.

Mitchell, R. C., Panzarello, A., Grynkiewicz, A., \& Galupo, M. P. (2015). Sexual minority and heterosexual former foster youth: A comparison of abuse experiences and trauma-related beliefs. Journal of Gay \& Lesbian Social Services, 27, 1-16.

Mohatt, N. V., Thompson, A. B., Thai, N. D., \& Tebes, J. K. (2014). Historical trauma as public narrative: A conceptual review of how history impacts present-day health. Social Science \& Medicine, 106, 128-136.

Mustanski, B., Andrews, R., \& Puckett, J. A. (2016). The effects of cumulative victimization on mental health among lesbian, gay, bisexual, and transgender adolescents and young adults. American Journal of Public Health, 106, 527-533.

Mustanski, B. S., Garofalo, R., \& Emerson, E. M. (2010). Mental health disorders, psychological distress, and suicidality in a diverse sample of lesbian, gay, bisexual, and transgender youths. American Journal of Public Health, 100, 2426-2432.

Newport, F. (2018). In U.S., estimate of LGBT population rises to 4.5\%. Washington, D.C.: Gallup. Retrieved https://news.gallup.com/poll/234863/estimate-lgbt-populationrises.aspx 
Nowell, L. S., Norris, J. M., White, D. E., \& Moules, N. J. (2017). Thematic analysis: Striving to meet the trustworthiness criteria. International Journal of Qualitative Methods, 16, 1-13.

O’Donnell, M. L., Schaefer, I., Varker, T., Kartal, D., Forbes, D., Bryant, R. A. A., ... Steel, Z. (2017). A systematic review of person-centered approaches to investigating patterns of trauma exposure. Clinical Psychology Review, 57, 208-225.

Park, C. L., \& Gutierrez, I. A. (2013). Global and situational meanings in the context of trauma: Relations with psychological well-being. Counselling Psychology Quarterly, 26, 8-25.

Russell, G. M., Bohan, J. S., McCarroll, M. C., \& Smith, N. G. (2011). Trauma, recovery, and community: Perspectives on the long-term impact of anti-LGBT politics. Traumatology, 17, 14-23.

Ryan, C., Huebner, D., Diaz, R. M., \& Sanchez, J. (2009). Family rejection as a predictor of negative health outcomes in white and Latino lesbian, gay, and bisexual young adults. Pediatrics, 123, 346-352.

Ryan, C., Russell, S. T., Huebner, D., Diaz, R., \& Sanchez, J. (2010). Family acceptance in adolescence and the health of LGBT young adults. Journal of Child and Adolescent Psychiatric Nursing, 23, 205-213.

Saldaña, J. (2015). The coding manual for qualitative researchers. Sage.

Sandelowski, M., \& Leeman, J. (2012). Writing usable qualitative health research findings. Qualitative Health Research, 22, 1404-1413.

Schmitz, R. M., \& Tyler, K. A. (2018). The complexity of family reactions to identity among homeless and college lesbian, gay, bisexual, transgender, and queer young adults. Archives of Sexual Behavior, 47(4), 1195-1207. 
Schmitz, R. M., \& Tabler, J. (2019). Health services and intersections of care: promises and pitfalls experienced by LGBTQ+ Latino/a emerging adults. Journal of LGBT Youth, 122.

Schmitz, R. M., Robinson, B. A., Tabler, J., Welch, B., \& Rafaqut, S. (2020). LGBTQ+ Latino/a young people's interpretations of stigma and mental health: An intersectional minority stress perspective. Society and Mental Health, 10, 163-179.

Shaffer, A., Yates, T. M., \& Egeland, B. R. (2009). The relation of emotional maltreatment to early adolescent competence: developmental processes in a prospective study. Child Abuse and Neglect, 33, 36-44.

Singh, A. A. (2017). Understanding trauma and supporting resilience with LGBT people of color. In Trauma, Resilience, and Health Promotion in LGBT Patients (pp. 113-119). Springer.

Sterzing, P. R., Gartner, R. E., Goldbach, J. T., McGeough, B. L., Ratliff, G. A., \& Johnson, K. C. (2017). Polyvictimization prevalence rates for sexual and gender minority adolescents: Breaking down the silos of victimization research. Psychology of Violence, 9, 419-430.

Toomey, R. B., Huynh, V. W., Jones, S. K., Lee, S., \& Revels-Macalinao, M. (2017). Sexual minority youth of color: A content analysis and critical review of the literature. Journal of Gay \& Lesbian Mental Health, 21, 3-31.

Town, M. A., Walters, K. L., \& Orellana, E. R. (2018). Discriminatory distress, HIV risk behavior, and community participation among American Indian/Alaska Native men who have sex with men. Ethnicity \& Health, 1-13.

Van der Kolk, B. A. (2017). Developmental trauma disorder: toward a rational diagnosis for children with complex trauma histories. Psychiatric annals, 35, 401-408. 
Walters, K. L., Evans-Campbell, T., Simoni, J. M., Ronquillo, T., \& Bhuyan, R. (2006). “My spirit in my heart": Identity experiences and challenges among American Indian TwoSpirit women. Journal of Lesbian Studies, 10, 125-149.

Whitbeck, L. B., Hoyt, D. R., McMorris, B. J., Chen, X., \& Stubben, J. D. (2001). Perceived discrimination and early substance abuse among American Indian children. Journal of Health and Social Behavior, 42, 405-424.

Whitton, S. W., Newcomb, M. E., Messinger, A. M., Byck, G., \& Mustanski, B. (2019). A longitudinal study of IPV victimization among sexual minority youth. Journal of Interpersonal Violence, 34, 912-945.

Willmon-Haque, S., \& BigFoot, S. D. (2008). Violence and the effects of trauma on American Indian and Alaska Native populations. Journal of Emotional Abuse, 8, 51-66.

Yeager, K. A., \& Bauer-Wu, S. (2013). Cultural humility: Essential foundation for clinical researchers. Applied Nursing Research, 26, 251-256.

Footnotes

1 Acknowledging the harmful history of colonialist oppressions of Native peoples as well as the rich cultural diversity of tribes (Sovereign Nations), we use the term "Native" to be inclusive of people's subjective definitions of their indigeneity to include Native American, American Indian, and Indigenous, though we concentrate on North American Native populations (McKay, 2019).

2 We use the term "Two-Spirit" to acknowledge the expansive history and meanings of gender and sexuality among Native groups that has often been present in Native tribal traditions. The identity of Two-Spirit is often conceptualized as a way to both celebrate gender and sexual fluidity and promote an anti-colonialist perspective through its more contemporary adoptions (Walters et al., 2006). 